\title{
Development of NOx Sensors for Heavy Vehicle Applications
}

Timothy R. Armstrong, David L. West, Fred C. Montgomery

Oak Ridge National Laboratory

CRADA No. ORNL 01-0627

with Ford Motor Company

Final Report 


\section{Introduction}

The primary gaseous pollutants (excluding $\mathrm{CO}_{2}$ ) produced by combustion of lowsulfur diesel fuel oxides of nitrogen $\left(\mathrm{NO}_{x}\right)$, carbon monoxide $(\mathrm{CO})$, and hydrocarbons $\left(\mathrm{C}_{y} \mathrm{H}_{z}\right)$. The last two of these can be readily ameliorated by an oxidation catalyst in the $\mathrm{O}_{2^{-}}$rich environment of diesel exhaust but $\mathrm{NO}_{x}$ can not.[1] For this reason $\mathrm{NO}_{x}$ remediation strategies such as selective catalytic reduction (SCR) $[2,3]$ and the lean $\mathrm{NO}_{x}$ trap (LNT $[4,5]$ are being actively pursued. The ideal implementation of these strategies would employ $\mathrm{NO}_{x}$ sensors to control reagent injection in the case of SCR and trap regeneration in the case of LNT.

Two different $\mathrm{NO}_{x}$ sensors for this application are at or near commercialization: An amperometric $\mathrm{NO}_{x}$ sensor developed by NGK [6] and a "mixed potential" $\mathrm{NO}_{x}$ sensor developed by Riken [7]. The NGK sensor works by passing the sampled exhaust through a series of two chambers. In the first chamber $\mathrm{O}_{2}$ is pumped from the exhaust and in the second, $\mathrm{NO}_{x}$ is decomposed electrochemically and the current from this decomposition is measured in order to determine $\left[\mathrm{NO}_{x}\right]$. Since the $\mathrm{NO}_{x}$ concentrations can be small, on the 10 's of ppm levels, the currents produced by decomposing the $\mathrm{NO}_{x}$ can be small and difficult to measure accurately. The Riken sensor functions by passing the exhaust over a "conversion electrode" that converts the $\mathrm{NO}_{x}$ to $\mathrm{NO}_{2}$. This $\mathrm{NO}_{2}$ is then sensed by a mixed potential sensing element.[8-10]

Researchers at Ford evaluated the NGK sensor and observed the above shortcoming (poor for low $\left[\mathrm{NO}_{x}\right]$ ) as well as others [11] (e.g., asymmetric response to NO vs. $\mathrm{NO}_{2}$ ) and were unable to obtain samples of the Riken sensor. Therefore a CRADA was initiated between Ford an ORNL to investigate the development of $\mathrm{NO}_{x}$ sensors for diesel exhaust applications.

\section{Experimental approach and results}

\subsection{General experimental approach}

Sensors for this application have to be able to withstand the high operating temperatures encountered in exhaust. For this reason virtually all the sensing techniques employed throughout the investigation were electrochemical in nature with yttriastabilized zirconia (YSZ) as the substrate/electrolyte. These substrates (usually $\sim 1.5 \mathrm{~cm}$ diameter, $\sim 0.1 \mathrm{~cm}$ thick) were either produced in-house at ORNL or obtained from Ford. In order to produce sensing elements electrodes (usually noble metals or oxides) were screen-printed onto the YSZ substrates and fired at temperatures around $1000{ }^{\circ} \mathrm{C}$. Usually the electrodes were on one broad face of the substrate.

Testing was carried out in a tube furnace to simulate the elevated temperature service. Fixtures were machined from bisque alumina to provide means of contacting the electrodes with Pt wire, and a commercial gas mixing unit (Environics) was used to mix $\mathrm{N}_{2}, \mathrm{O}_{2}, \mathrm{NO}$, etc. as required for the test at hand. A schematic of the experimental setup is shown in Fig. 1. 


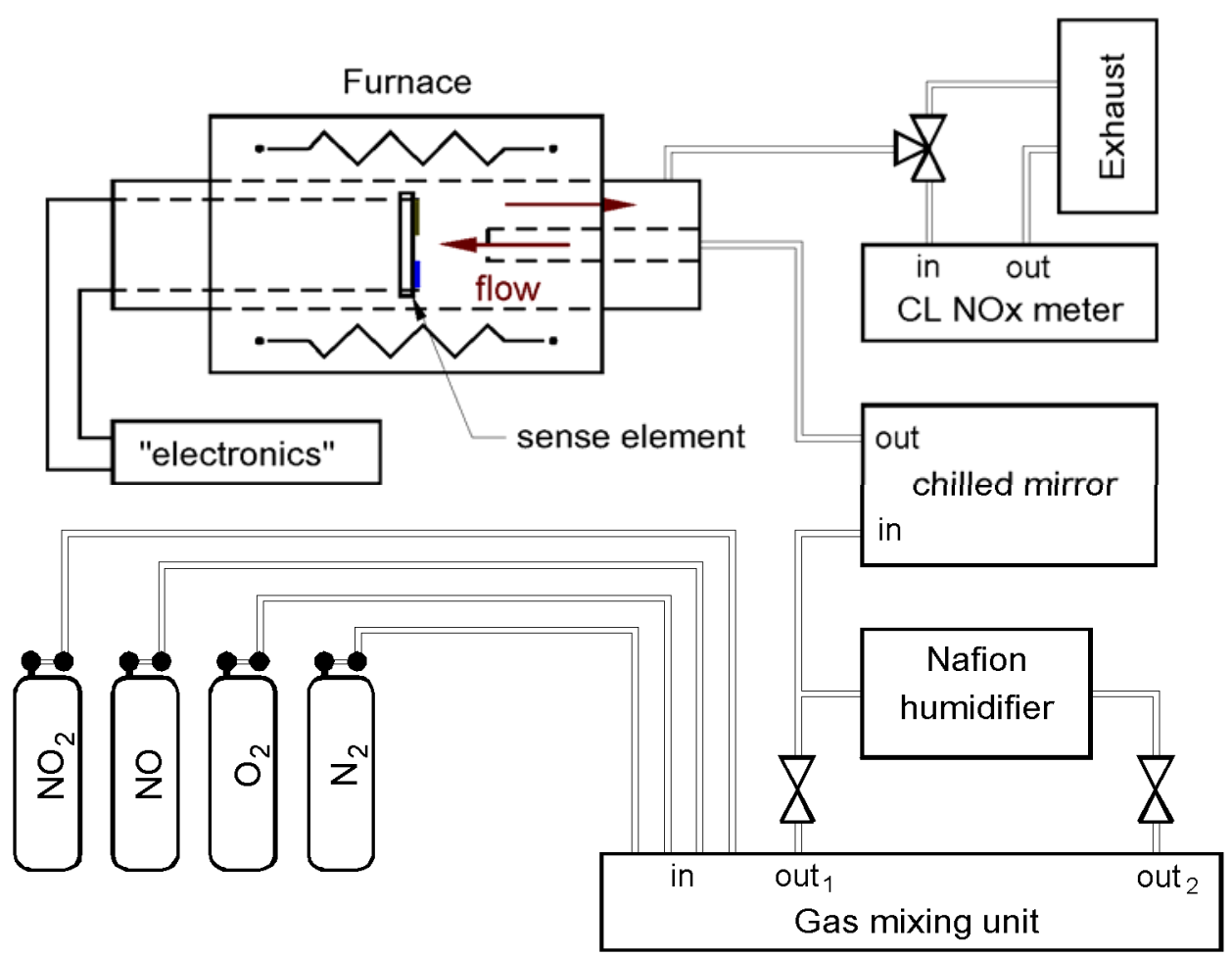

Figure 1: Schematic of experimental setup for $\mathrm{NO}_{x}$ sensing element characterization.

During the course of this project three different techniques were explored for $\mathrm{NO}_{x}$ sensing. The first technique was the "mixed-potential" approach mentioned above. The second was application of electrical stimuli (usually a DC current or voltage) to sensing elements with dissimilar electrodes. The third and final technique employed was application of electrical stimuli to sensing elements with compositionally identical electrodes. All three methods will be discussed in the following section.

\subsection{Mixed potential sensing}

In this type of sensing usually the voltage is monitored between two dissimilar electrodes exposed to the sample gas, or between one electrode exposed to the sample gas and a reference. The experiments done at ORNL were virtually all of the former type and the sensing element geometries employed are shown in Fig. 2. The geometry in Fig. 2a is similar to one described my Miura et al. [12] and during the course of the present investigation elements of this geometry with $\mathrm{Pt}, \mathrm{Ag} / \mathrm{Pd}$, and $\mathrm{La}_{0.85} \mathrm{Sr}_{0.15} \mathrm{CrO}_{3}$ as the "Metal or conducting oxide" were fabricated and tested. Oxides used as the partial covering on one electrode were primarily perovskites (e.g. $\mathrm{La}_{0.6} \mathrm{Sr}_{0.4} \mathrm{Co}_{0.2} \mathrm{Fe}_{0.8} \mathrm{O}_{3}$ ) and spinels (e.g. $\mathrm{NiCr}_{2} \mathrm{O}_{4}$ ). For the geometry in Fig. $2 \mathrm{~b}$ the perovskite $\mathrm{La}_{0.85} \mathrm{Sr}_{0.15} \mathrm{CrO}_{3}$ (LSC) and some binary oxides (e.g. $\mathrm{ZnO})$ were used in combination with $\mathrm{Pt}$ 


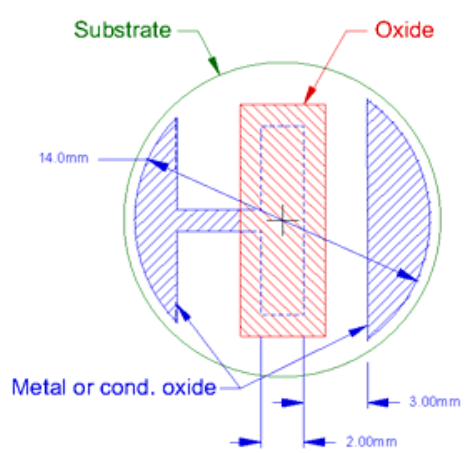

(a)

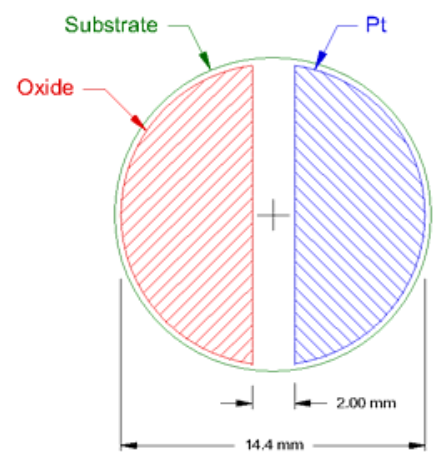

(b)

Figure 2: Element geometries with dissimilar electrodes.

The $\mathrm{NO}_{x}$ sensing performance of these mixed potential elements was similar to that described in the literature (for example [13]): Strong responses to $\mathrm{NO}_{2}$ were observed but the response to NO was much weaker and opposite in sign. Some representative data are shown in Fig. 3. Since combustion exhausts typically contain $\mathrm{NO}$ and $\mathrm{NO}_{2}$ in an unknown ratio (hence " $\mathrm{NO}_{x}$ ") it these elements would require that the sensor have some provision for converting the $\mathrm{NO}_{x}$ to a fixed $\left[\mathrm{NO}_{2}\right]$ : $[\mathrm{NO}]$ ratio (as is the case in the Riken sensor mentioned previously [7]). Much of the ORNL work on these type of sensing elements was detailed in a conference paper [14] and two publications $[15,16]$.
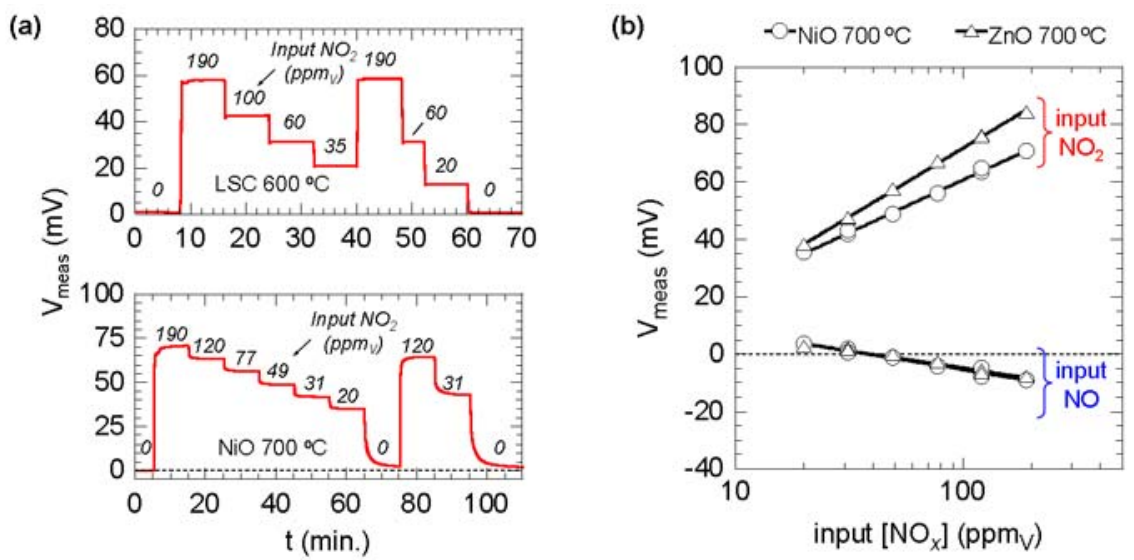

Figure 3: $\mathrm{NO}_{x}$ sensing behavior of "mixed-potential" sensing elements in 7\% $\mathrm{O}_{2}$. These elements had the oxide indicated paired with $\mathrm{Pt}$ in the geometry of

Fig. 2b. $\mathrm{LSC}=\mathrm{La}_{0.85} \mathrm{Sr}_{0.15} \mathrm{CrO}_{3}$.

\subsection{Use of electrical stimuli on elements with dissimilar electrodes}

Several investigators $[10,17,18]$ have reported on applying electrical stimuli ("bias") to electrochemical $\mathrm{NO}_{x}$ sensing elements. Similar work was carried out during the course of this CRADA on elements with the geometries shown in Fig. 2a) and b). Typically, a DC current source (Keithley 2400) was used to impose a fixed current across the electrodes and the DC potential required to maintain this current was monitored, or a fixed potential was maintained across the electrodes and the DC current monitored. 
(These two techniques gave nearly identical results if the measurements were converted to $\mathrm{DC}$ resistances $\left(\mathrm{V}_{\text {meas }} / \mathrm{I}_{\mathrm{app}}\right.$ or $\left.\mathrm{V}_{\text {app }} / \mathrm{I}_{\text {meas }}\right)$.)

For several different materials combinations it was observed that if the bias condition was such that the partially oxide-covered (Fig. 2a) or oxide (Fig. 2b) electrode was positive with respect to the Pt electrode the response to NO was enhanced (Often to the point that the element became "NO-selective"). Some data illustrating this behavior is shown in Fig. 4. In order to rationalize this behavior, it was considered that with "positive" bias oxygen ions are being supplied to the partially oxide-covered or oxide electrode. This may be facilitating the oxidation of NO. Unfortunately we were unable to design and carry out experiments to elucidate the mechanism responsible for the enhanced NO response. Unexplained also was the observation that some oxides evaluated would not display an enhanced NO response as is seen in Fig. 4.
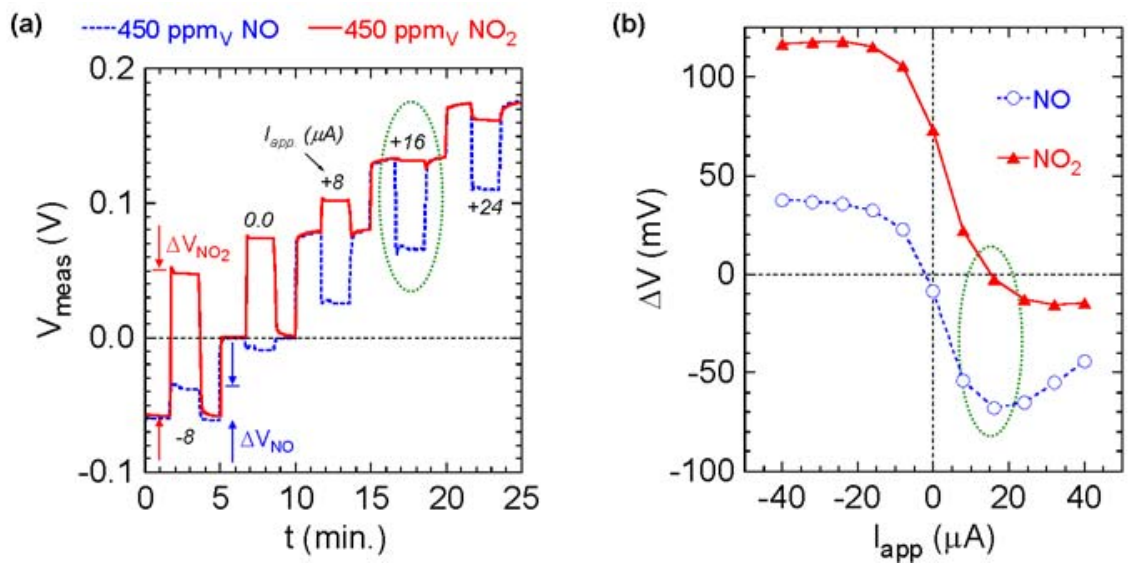

Figure 4: Sensing behavior with applied electrical stimulus. In a is shown the measured voltage ( $\mathrm{V}_{\text {meas }}$ ) as $450 \mathrm{ppm}$ of $\mathrm{NO}$ or $\mathrm{NO}_{2}$ is pulsed at different applied current levels. The computed changes in $\mathrm{V}_{\text {meas }}$ as a function of $\mathrm{I}_{\text {app }}$ are shown in b. Data collected at $600{ }^{\circ} \mathrm{C}, 7 \mathrm{vol} \% \mathrm{O}_{2}$, balance $\mathrm{N}_{2}$

The sensing performance of these "biased" elements for NO was examined in fair detail, and some of the operational characteristics were found to be:

- The applied voltage at which "NO-selective" behavior was observed was usually around $+0.1 \mathrm{~V}$. (Bare Pt electrode at a lower potential than the partially oxidecovered (Fig. 2a) or oxide (Fig. 2b) electrode.)

- The enhancement of the NO response relative to $\mathrm{NO}_{2}$ typically weakened as the concentration decreased to near $\sim 20 \mathrm{ppm}$.

- At lower concentrations the response to NO tended to become linear, and this linear range would extend to higher concentrations as the operating temperature was increased.

- The sensing elements would typically become more resistive during operation, leading to "drift" sensor response.

- For samples with the geometry shown in Fig. 2a, varying the $\mathrm{O}_{2}$ content between $\sim 5$ and $20 \%$ produced little change in the sensing signal with or without NO 
present. In contrast, samples with the Fig. $2 \mathrm{~b}$ geometry showed a response to varying $\left[\mathrm{O}_{2}\right]$ was a decreasing function of [NO].

- The sensing performance of elements of the type shown in Fig. 2b appeared to be insensitive to minor variations in electrode geometry.

These observations were discussed in detail in two publications $[16,19]$. Two conference presentations were also made discussing the performance of these sensing elements.[20,21]

\subsection{Use of electrical stimuli on elements with compositionally identical electrodes}

These types of sensing elements were the last to be investigated, however as the project evolved these became the primary focus with the most promise. Samples with a host of different geometries were made, but the geometry that was investigated the most intensely is shown in Fig. 5. This geometry consists of two electrodes, both produced in a single screen-printing and firing step. Samples of this geometry showed qualitatively similar behavior to that shown in Fig. 3 when operated without electrical stimuli-an $\mathrm{NO}_{2}$ response that was stronger and opposite in sign than that to NO. The voltages produced however were small, usually less than $10 \mathrm{mV}$ for $450 \mathrm{ppm} \mathrm{NO}_{2}$ at $600{ }^{\circ} \mathrm{C}$.

With the application of electrical stimuli a most surprising and unexpected result was found as shown in Fig. 6. Figure 6a shows that at small positive applied currents (the larger area electrode at a higher potential than the smaller area electrode (Fig. 5)) the response of the sensing element to $77 \mathrm{ppm} \mathrm{NO}$ and $\mathrm{NO}_{2}$ was approximately the same. This nearly equal response could be maintained over approximately a decade of concentration (20 ppm $\leq\left[\mathrm{NO}_{x}\right] \leq 200 \mathrm{ppm}$ ) as shown in Fig. 6b. Behavior of this sort by a sensing element is often referred to as "total $\mathrm{NO}_{x}$ " sensing and it is a highly desirable characteristic because the relative abundance of $\mathrm{NO}$ and $\mathrm{NO}_{2}$ in exhaust is rarely known with certainty.

Unfortunately, as was the case above, attempts to elucidate the sensing mechanism of these elements were unsuccessful. However, the following general observations regarding the sensing behavior of these elements were made:

- It was possible to obtain near "total $\mathrm{NO}_{x} "$ behavior with a number of oxides.

- The closest to "total $\mathrm{NO}_{x}$ " behavior was usually observed at small positive potentials $(\sim 50-100 \mathrm{mV})$.

- At lower $\mathrm{NO}_{x}$ concentrations $(<\sim 20 \mathrm{ppm})$, the $\mathrm{NO}_{2}$ response would invariably become greater in magnitude than the NO response.

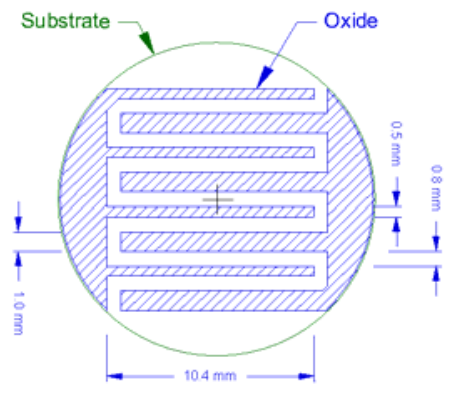

Figure 5: Element geometry for "compositionally identical oxide electrodes".

- The sensing elements would typically become more resistive during operation, leading to "drift" in the element response.

- These elements showed a response to varying $\left[\mathrm{O}_{2}\right]$ was a decreasing function of $\left[\mathrm{NO}_{x}\right]$, and varying $\left[\mathrm{O}_{2}\right]$ (in the absence of $\mathrm{NO}_{x}$ ) from $7-20$ vol\% would cause changes on the order of $30 \%$ to the sensor output. 
These observations were summarized in a publication [22] and also formed the basis of two conference presentations $[23,24]$. In addition to the information presented there, the following observations regarding these types of sensing elements were made:

- Lanthanum chromite electrodes with alkaline earth modifications on the "A" site $\left(\mathrm{La}_{0.85} \mathrm{Sr}_{0.15} \mathrm{CrO}_{3}, \mathrm{La}_{0.80} \mathrm{Ca}_{0.20} \mathrm{CrO}_{3}\right.$, etc.) were unstable with respect to phase decomposition if significant moisture was present. A B-site substituted chromite $\left(\mathrm{LaCr}_{0.95} \mathrm{Mg}_{0.05} \mathrm{O}_{3}\right)$ however was stable.

- The elements responded to varying $\left[\mathrm{H}_{2} \mathrm{O}(\mathrm{g})\right]$, with the effect of varying $\left[\mathrm{H}_{2} \mathrm{O}(\mathrm{g})\right]$ from 0.5 to $1.5 \%$ often being commensurate with the response to $50 \mathrm{ppm}$ NO.

- Significant responses also were observed to $\mathrm{C}_{3} \mathrm{H}_{6}, \mathrm{NH}_{3}, \mathrm{SO}_{2}$, and $\mathrm{H}_{2}$ (although this was a function of the applied current level). $\mathrm{CO}$ tended to be less of an interferent.

(a)

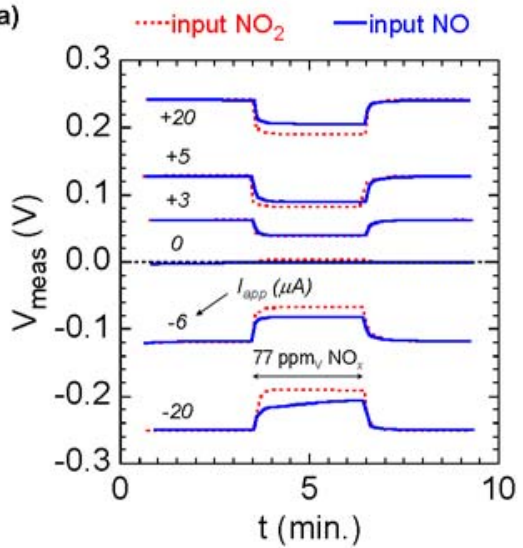

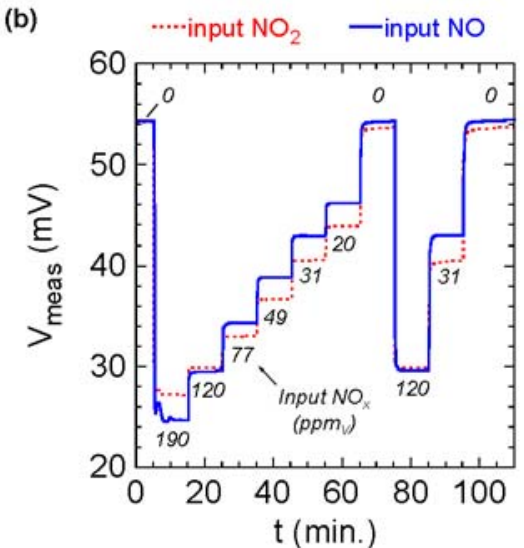

Figure 6: a shows the effect of 77 ppm $\mathrm{NO}$ and $\mathrm{NO}_{2}$ on $\mathrm{V}_{\text {meas }}$ at different $\mathrm{I}_{\mathrm{app}}$ for a sensing element with the geometry of Fig. Error! Reference source not found. The $\mathrm{NO}_{x}$ sensing performance at fixed $\mathrm{I}_{\text {app }}$ is shown in $\mathrm{b}$. Data collected at $600{ }^{\circ} \mathrm{C}, 7 \mathrm{vol} \% \mathrm{O}_{2}$, balance $\mathrm{N}_{2}$.

\section{Conclusions}

In this work "mixed-potential" sensing elements w/ very strong $\mathrm{NO}_{2}$ responses (Fig. 3), "biased" sensing elements with strong NO responses (Fig. 4), and "total $\mathrm{NO}_{x}$ " sensing elements were demonstrated. The last two types would be more directly applicable to $\mathrm{NO}_{x}$ sensing in diesel and lean burn engine exhausts as most of the $\mathrm{NO}_{x}$ in these exhausts is believed to be NO.

The "total $\mathrm{NO}_{x}$ " elements were by far the most heavily investigated type of element, and the main shortcomings of these appeared to be tendency to drift and cross-sensitivity to varying $\mathrm{O}_{2}$ and $\mathrm{H}_{2} \mathrm{O}(\mathrm{g})$.

\section{References}

1. J. T. Woestman and E. M. Logothetis, "Controlling automotive emissions," The Industrial Physicist 1 (1995) pp. 21-24. 
2. Z. M. Liu and S. I. Woo, "Recent advances in catalytic DeNO(x) science and technology," Catalysis Reviews-Science and Engineering 48 (2006) pp. 43-89.

3. G. Busca, L. Lietti, G. Ramis, and F. Berti, "Chemical and mechanistic aspects of the selective catalytic reduction of $\mathrm{NO}_{x}$ by ammonia over oxide catalysts: A review," Applied Catalysis B-Environmental 18 (1998) pp. 1-36.

4. M. Hilgendorff, "NO$x$ abatement by catalytic traps: on the mechanism of $\mathrm{NO}_{x}$ trapping under automotive conditions," Topics in Catalysis 30-31 (2004) pp. 155-159.

5. R. Burch, "Knowledge and know-how in emission control for mobile applications," Catalysis Reviews-Science and Engineering 46 (2004) pp. 271-333.

6. N. Kato, H. Kurachi, and Y. Hamada, "Thick Film $\mathrm{ZrO}_{2}$ Sensor for the Measurement of Low $\mathrm{NO}_{x}$ Concentration," SAE Technical Paper Series (1998).

7. A. Kunimoto, M. Hasei, Y. Yan, Y. Gao, T. Ono, and Y. Nakanouchi, "New Total$\mathrm{NO}_{x}$ Sensor Based on Mixed Potential for Automobiles," SAE Technical Paper Series (1999).

8. N. Miura, H. Kurosawa, M. Hasei, G. Lu, and N. Yamazoe, "Stabilized zirconiabased sensor using oxide electrode for detection of $\mathrm{NO}_{\mathrm{x}}$ in high-temperature combustion-exhausts," Solid State Ionics 86-88 (1996) pp. 1069-1073.

9. F. H. Garzon, R. Mukundan, and E. L. Brosha, "Solid-state mixed potential gas sensors: Theory, experiments, and challenges," Solid State Ionics 136-7 (2000) pp. 633-638.

10. N. Miura, G. Lu, and N. Yamazoe, "Progress in mixed-potential type devices based on solid electrolyte for sensing redox gases," Solid State Ionics 136-7 (2000) pp. 533542.

11. D. Kubinski and R. Soltis, 2003.

12. N. Miura, G. Lu, M. Ono, and N. Yamazoe, "Selective detection of NO by using an amperometric sensor based on stabilized zirconia and oxide electrode," Solid State Ionics 117 (1999) pp. 283-290.

13. G. Lu, N. Miura, and N. Yamazoe, "High-temperature sensors for $\mathrm{NO}$ and $\mathrm{NO}_{2}$ based on stabilized zirconia and spinel-type oxide electrodes," Journal of Materials Chemistry 7 (1997) pp. 1445-1449.

14. D. L. West, F. C. Montgomery, and T. R. Armstrong, "Electrode materials for mixedpotential $\mathrm{NO}_{x}$ sensors," presented at 28th International Conference on Advanced Ceramics and Composites, Cocoa Beach, FL, 2004.

15. D. L. West, F. C. Montgomery, and T. R. Armstrong, "Use of $\mathrm{La}_{0.85} \mathrm{Sr}_{0.15} \mathrm{CrO}_{3}$ in high-temperature $\mathrm{NO}_{x}$ sensing elements," Sensors and Actuators B 106 (2005) pp. 758-765.

16. D. L. West, F. C. Montgomery, and T. R. Armstrong, "'NO-selective" $\mathrm{NO}_{x}$ sensing elements for combustion exhausts," Sensors and Actuators B-Chemical 111 (2005) pp. 84-90. 
17. K.-Y. Ho, M. Miyayama, and H. Yanagida, "NO $\mathrm{NO}_{x}$ response properties in DC Current of $\mathrm{Nd}_{2} \mathrm{CuO}_{4} / 4 \mathrm{YSZ} / \mathrm{Pt}$ element," J. Ceram. Soc. Jpn. 104 (1996) pp. 995-999.

18. V. Coillard, H. Debeda, C. Lucat, and F. Menil, "Nitrogen monoxide detection with a planar spinel coated amperometric sensor," Sens. Actuators, B: 78 (2001) pp. 113118.

19. D. L. West, F. C. Montgomery, and T. R. Armstrong, "Electrically biased $\mathrm{NO}_{x}$ sensing elements with coplanar electrodes," Journal of the Electrochemical Society 152 (2005) pp. H74-H79.

20. D. L. West, F. C. Montgomery, and T. R. Armstrong, "Electrically biased $\mathrm{NO}_{x}$ sensing elements with co-planar, multi-layered electrodes," presented at $205^{\text {th }}$ Meeting of the Electrochemical Society, San Antonio, TX, 2004.

21. D. L. West, F. C. Montgomery, and T. R. Armstrong, "NO Selective Sensing Elements for Combustion Exhausts," presented at Eurosensors XVIII, Rome, Italy, 2004.

22. D. L. West, F. C. Montgomery, and T. R. Armstrong, "'Total $\mathrm{NO}_{x}$ " sensing elements with compositionally identical oxide electrodes," Journal of the Electrochemical Society 153 (2006) pp. H23-H28.

23. D. L. West, F. C. Montgomery, and T. R. Armstrong, "'Total $\mathrm{NO}_{x}$ " sensing elements with compositionally identical oxide electrodes," presented at $207^{\text {th }}$ Meeting of the Electrochemical Society, Quebec City, Quebec, CA, 2005.

24. D. L. West, F. C. Montgomery, and T. R. Armstrong, "DC Electrical-biased, all-oxide $\mathrm{NO}_{x}$ sensing elements for use at $873 \mathrm{~K}$," presented at 29th International Conference on Advanced Ceramics and Composites, Cocoa Beach, FL, 2005.

25. D. L. West, F. C. Montgomery, and T. R. Armstrong, "High-T $\mathrm{NO}_{x}$ sensing elements using conductive oxides and Pt," presented at ICEF2004, 2004 Fall Technical Conference of the ASME Internal Combustion Engine Division, Long Beach, CA, 2004. 